\title{
SPINNING EXERCISE INTENSITAS SEDANG MENURUNKAN GEJALA DISMENORE PRIMER MAHASISWI DIII KEBIDANAN
}

\author{
Hani Oktafiani ${ }^{1}$, Hadi Susiarno ${ }^{2)}$, Vita Murniarti ${ }^{3)}$ \\ ${ }^{1)}$ Program Studi DIII Kebidanan Universitas Bhakti Kencana Bandung \\ ${ }^{2), 3)}$ Departemen Obstetri dan Gynekologi FK Unpad \\ E-mail: h.oktafiani@yahoo.com
}

\begin{abstract}
Some young women including female students in Indonesia are still not free from complaints of dysmenorrbea syndrome. One of the effects of dysmenorrhea is a decrease in learning concentration and daily productivity. Activity that can be pursued is to change lifestyles to be more active in physical exercise, one of which is exercise training. The purpose of this study was to analyze the effect of moderate-intensity spinning exercise on reducing the symptoms of primary dysmenorrhea pain in female college students. This quantitative research uses a quasi-experimental design pre-test post-test design. Studies subjects numbered 32 where the control and intervention groups each consisted of 16 respondents. The intervention that will be given to the intervention group is a moderate intensity spinning exercise for 3 weeks with the FITT principle. The research data were analyzed by Mann Whitney and Wilcoxon statistical tests. The results of the analysis showed a decrease in dysmenorrhea pain symptoms before the intervention there was no significant difference $(p>0.05)$, whereas after the administration of the intervention showed there were significant differences in the intervention and control groups with a value of $p=0.001$. The influence of moderate-intensity spinning exercise can reduce the symptoms of dysmenorrhea pain by $66 \%$. Educational institutions can implement policies on the use of spinning tools in the environment of students and educate these tools to adolescents in the target area given their effective use to reduce menstrual pain.
\end{abstract}

Keywords: The spinning exercise of moderate intensity; dysmenorrhea.

\begin{abstract}
ABSTRAK
Beberapa remaja putri termasuk mahasiswi di Indonesia masih belum terlepas dari keluhan sindrom dismenore. Salahsatu dampak dismenore yaitu turunnya konsentrasi belajar dan produktivitas harian. Aktifitas yang dapat diupayakan yaitu dengan merubah gaya hidup agar lebih aktif melakukan olah fisik salah satunya latihan berolahraga. Tujuan penelitian ini adalah menganalisis pengaruh spinning exercise intensitas sedang terhadap penurunan gejala
\end{abstract}

Cara mengutip: Oktafiani, Hani., Susiarno, Hadi \& Murniarti, Vita. (2020). Spinning Exercise Intensitas Sedang Menurunkan Gejala Disminore Primer Mahasiswi DIII Kebidanan Care:Jurnal Ilmiah Ilmu Kesehatan, 8(1), 92-103 
nyeri dismenore primer pada mahasiswi. Penelitian kuantitatif ini menggunakan rancangan quasi eksperimen pre test-post test design. Subjek penelitian berjumlah 32 diamana group kontrol dan intervensi masing masing terdiri dari 16 responden. Intervensi yang akan diberikan pada kelompok intervensi yaitu spinning exercise intensitas sedang selama 3 minggu dengan prinsip FITT. Data penelitian dianalisis dengan uji statistik Mann Whitney dan Wilcoxon. Hasil analisis diperoleh penurunan gejala nyeri dismenore sebelum intervensi tidak ada perbedaan yang bermakna $(\mathrm{p}>0,05)$, sedangkan setelah pemberian intervensi menunjukkan ada perbedaan yang bermakna pada kelompok intervensi dan kontrol dengan nilai $\mathrm{p}=0,001$. Pengaruh spinning exercise intensitas sedang dapat penurunan gejala nyeri dismenore sebesar $66 \%$. Institusi pendidikan dapat menerapkan kebijakan penggunaan alat spinning di lingkungan mahasiswa serta mengedukasikan alat tersebut kepada remaja di wilayah binaan mengingat pemanfaatannya yang efektif untuk menurunkan nyeri menstruasi.

Kata Kunci : Spinning exercise intensitas sedang; Dismenore

\section{PENDAHULUAN}

Meningkatnya keluhan fisik dapat menurunkan produktivitas sumber daya manusia. Salah satu komponen masyarakat adalah remajayang jumlah populasinya tercatat di Indonesia sebesar 23.902.077 juta jiwa.. Remaja merupakan penduduk dengan usia pada rentang 10-24 tahun dengan kriteria belum menikah. Pusat Riset dan Pengembangan Kependudukan - BKKBN dalam Kajian Profil Penduduk Remaja. Remaja haruslah energik, produktif dan terbebas dari gangguan ataupun keluhan kesehatan. Namun pada kenyataannya beberapa remaja putri di Indonesia masih belum terlepas dari sindrom dismenore yang harus dihadapi setiap bulannya. Dismenore primer merupakan suatu fenomena simptomatik berupa nyeri normal saat haid, yang jika tidak ditatalaksana dengan baik maka akan meningkatkan dampak merugikan terhadap aspek psikologis, sosial dan ekonomi sehingga akan mempengaruhi kualitas hidup remaja itu sendiri.

Prevalensi dismenorrhea primer pada beberapa riset diberbagai negara menunjukkan frekuensi yang tinggi, World Health Organization (WHO) mencatat ratarata kejadian 16,8 hingga 81\% pada wanita muda. Pada tahun 2016 di Indonesia tercatat angka kejadian dismenore sebesar $64,25 \%$ yang terdiri dari $54,89 \%$ dismenore primer dan 9,36\% dismenore sekunder. Sindrom dismenore ini terjadi juga pada mahasiswi kebidanan di Politeknik Kesehatan TNI AU Ciumbuleuit Kota Bandung. Tercatat 47 kasus dismenore intensitas sedang dari 65 mahasiswi, sisanya yaitu dengan intensitas 
ringan juga berat. Hal ini berdampak pada turunnya konsentrasi belajar sebesar 38\% dan gangguan beraktifitas. Bidan sebagai salah satu tenaga kesehatan yang memiliki posisi penting dan strategis dalam meningkatkan derajat kesehatan wanita berperan untuk melakukan tindakan atau manajemen untuk mengatasi dismenore primer sesuai dengan Permenkes nomor 28 tahun 2017 BAB III pasal 18 bahwa dalam penyelenggaraan Praktik Kebidanan, bidan memiliki kewenangan untuk memberikan pelayanan kesehatan reproduksi remaja.Salah satu penyebab utama dismenore primer adalah peningkatan produksi prostaglandin uterus yang menimbulkan kontraksi. Terapi non farmakologi yang paling dekat dan mudah untuk dilakukan oleh setiap wanita adalah modifikasi gaya hidup. Diantara terapi yang dapat dilakukan untuk memodifikasi gaya hidup adalah dengan melakukan latihan fisik melalui olah raga.

GERMAS hadir sebagai upaya pemerintah dalam meningkatkan perilaku sehat bagi masyarakat yang salah satu programnya yaitu melakukan aktivitas fisikatau berolah raga. Upaya nonfarmakologi efektif untuk menurunkan nyeri dismenore yaitu dengan latihan olah raga aerobik. Riset Marsida dkk. pada tahun 2013 mengemukakan ketika seseorang melakukan olah raga aerobikdengan teratur dan terukur maka akan terjadi pelepasan hormon endorphin didalam tubuh yang akan mengaktifkan satu jalur inhibisi nyeri desendens (ke aliran darah) dan menghambat transmisi serta pengaturan nyeri sehingga dapat berdampak pada penurunan nyeri dismenore. Aktifitas rutin berupa senam erobik sudah dilaksanakan namun dianggap belum bisa menjawab permasalah dismenore yang dialami mahasiswi. Spinning exercise adalah salah satu bentuk olah raga aerobik yang diadaptasi dari olah raga bersepeda menggunakan sepeda statis. Riset mengenai pemanfaatannya terhadap pengurangan gejala PMS khususnya dismenore masih terbatas. Dengan memberikan spinning exercise sesuai intensitas yang terukur, diharapkan olah raga ini dapat diterima dikalangan mahasiswi untuk memberikan efek relaksasi dan rekreasi sehingga dapat mengatasi permasalahan dismenore secara menyenangkan.

\section{METODE PENELITIAN}

Penelitian ini menggunakan metode kuantitatif, untuk menjawab pengaruh latihan spinning intensitas sedang sebagai variabel bebas terhadap penurunan gejala 
nyeri dismenore primer sebagai variabel terikat. Jenis penelitian kuasi eksperimental dengan rancangan pre test post test control group design. Subjek penelitian di bagi dua kelompok dengan kriteria inklusi usia 18-20 tahun, skala dismenore primer 4-6, siklus menstruasi teratur dalam 3 bulan terakhir. Kelompok perlakuan diberikan intervensi latihan spinning intensitas sedang selama 9 kali latihan dengan interval waktu 1 hari dan sekali latihan selama 30 menit dengan pendampingan dari instruktur kebugaran. Sedangkan kelompok kontrol diistirahatkan tanpa melakukan aktivitas olah raga.

Data yang dikumpulkan terdiri dari data primer. Data kelompok kontrol yang diambil yaitu hasil pengukuran skala intensitas dan durasi dismenore serta lama menstruasi. Data Primer kelompok intervensi yaitu data skala intensitas dan durasi nyeri juga data denyut nadi selama latihan Spinning Exercise dari masingmasing responden. Instrumen yang digunakan dalam penelitian ini adalah berupa kuesioner skala VAS, sepeda statis, lembar catatan hasil kegiatan spinning. Mahasiswa yang telah ditentukan sebagai responden pada periode I menstruasi hari pertama mengisi kuesioner $V A S$ serta mengisi pertanyaan durasi dismenore pada hari pertama menstruasi(pre test). Setelah pengisian kuesioner responden diistirahatkan sampai dengan rasa nyeri hilang. Setelah nyeri hilang responden melakukan latihan spinning dengan pendampingan. Setelah melakukan latihan sebanyak 9 kali latihan, responden ditunggu periode II menstruasi hari pertama dan diberikan lagi kuesioner $V A S$ serta mengisi pertanyaan durasi dismenore (post test). Penelitian ini telah mendapatkan izin etik dari Komisi Etik Penelitian Universitas Bandung dengan surat nomor 20/UN6.KEP/EC/2019.

\section{HASIL}

Berdasarkan Tabel 1 sebagian besar responden pada kedua kelompok berusia 18 tahun, adapun lama menstruasi pada kelompok intervensi dan kelompok kontrol rata-rata selama 6-7 hari. Lama menstruasi pada kedua kelompok paling sebentar 5 hari dan paling lama 9 hari berada pada kelompok kontol. Menarche atau usia pertama menstruasi pada kelompok kontol dan kelompok intervensi rata-rata pada usia 11 tahun. Siklus menstruasi terpendek pada kelompok intervensi dan kontrol adalah 21 hari dan siklus terpanjang 29 hari dengan rata-rata siklus 24 hari. 
Tabel 1. Karakteristik Umum

\begin{tabular}{|c|c|c|c|}
\hline \multirow[b]{2}{*}{$\begin{array}{c}\text { Karakteristik } \\
\text { Responden }\end{array}$} & \multicolumn{2}{|c|}{ Kelompok Riset } & \multirow[b]{2}{*}{ Nilai $p^{*}$} \\
\hline & $\begin{array}{c}\text { Spinning } \\
\text { Intensitas } \\
\text { Sedang } \\
(\mathrm{n}=16)\end{array}$ & $\begin{array}{c}\text { Tidak } \\
\text { Melakukan } \\
\text { Spinning } \\
(\mathrm{n}=16)\end{array}$ & \\
\hline \multicolumn{4}{|l|}{ Usia (tahun) : } \\
\hline 18 tahun & 11 & 10 & 0,678 \\
\hline 19 tahun & 4 & 3 & \\
\hline 20 tahun & 1 & 3 & \\
\hline \multicolumn{4}{|l|}{ Usia menarche (tahun) : } \\
\hline Rerata (SD) & $12(0,7)$ & $11(0,8)$ & 0,114 \\
\hline Median & 11 & 11 & \\
\hline Rentang & $11-13$ & $11-13$ & \\
\hline \multicolumn{4}{|l|}{ Lama menstruasi (hari) : } \\
\hline Rerata (SD) & $6(0,9)$ & $6(1,0)$ & 0,739 \\
\hline Median & 6 & 7 & \\
\hline Rentang & $5-8$ & $5-9$ & \\
\hline \multicolumn{4}{|l|}{ Siklus menstruasi : } \\
\hline Rerata (SD) & $24(1,2)$ & $24(1,2)$ & 0,065 \\
\hline Median & 24 & 24 & \\
\hline Rentang & $21-29$ & $21-29$ & \\
\hline
\end{tabular}

Keterangan : *) berdasarkan uji Mann-Whitney, kecuali untuk usia dengan uji Chi-kuadrat

Berdasarkan Tabel 2 didapat bahwa pada pre test median skala nyeri 5 dengan rentang 4 - 6, baik pada kelompok intervensi maupun kempokok control $(\mathrm{p}=0,643)$. Pada post test kelompok yan mendapat intervensi median skala nyeri menurun menjadi 1 dengan rentang $0-3$, sedangkan pada kelompok kontrol median skala nyeri masih tetap sebesar 5 dengan rentang $4-6$, berdasarkan uji mann whitney nilai $\mathrm{p}<0,001$, artinya bahwa terdapat perbedaan skala nyeri pada post tes antara kelompok intervensi dan kelompok kontrol. Berdasarkan uji Wilcoxon, pada kelompok intervensi menunjukkan penurunan intensitas nyeri yang bermakna $(p<0,001)$, sedangkan pada kelompok kontrol tidak menunjukkan penurunan intensitas nyeri yang bermakna $(p=0,783)$.

Berdasarkan Tabel 3 diketahui bahwa pada pre test median durasi nyeri 12 jam dengan rentang 2 - 48 jam, baik pada kelompok intervensi maupun kempokok control $(p=0,729)$. Pada post test kelompok yan mendapat intervensi median durasi nyeri menurun menjadi 1 jam dengan rentang $0-24$ jam, sedangkan pada kelompok kontrol median durasi nyeri masih tetap sebesar 12 jam dengan rentang $2-24$, berdasarkan uji mann whitney nilai $\mathrm{p}=0,004$, artinya bahwa terdapat 
perbedaan durasi nyeri pada post tes antara kelompok intervensi dan kelompok kontrol. Berdasarkan uji Wilcoxon, pada kelompok intervensi menunjukkan penurunan durasi nyeri yang bermakna $(p=0,007)$, sedangkan pada kelompok kontrol menunjukkan penurunan durasi nyeri yang tidak bermakna $(p=0,655)$.

Tabel 2. Penurunanintensitas dismenore primer dua kelompok

\begin{tabular}{|c|c|c|c|}
\hline \multirow[b]{2}{*}{ Intensitas nyeri } & \multicolumn{2}{|c|}{$\begin{array}{c}\text { Latihan Spinning Intensitas } \\
\text { Sedang }\end{array}$} & \multirow[b]{2}{*}{ Nilai $p^{*}$} \\
\hline & $\begin{array}{c}\text { Melakukan } \\
\text { Latihan } \\
(\mathrm{n}=16)\end{array}$ & $\begin{array}{c}\text { Tidak } \\
\text { Latihan } \\
(\mathrm{n}=16)\end{array}$ & \\
\hline $\begin{array}{l}\text { Pre Test } \\
\text { Median } \\
\text { Rentang }\end{array}$ & $\begin{array}{c}5 \\
4-6\end{array}$ & $\begin{array}{c}5 \\
4-6\end{array}$ & $0,643^{*}$ \\
\hline $\begin{array}{l}\text { Post Test } \\
\text { Median } \\
\text { Rentang } \\
\end{array}$ & $\begin{array}{c}1 \\
0-3\end{array}$ & $\begin{array}{c}5 \\
4-6) \\
\end{array}$ & $<0,001 *$ \\
\hline Perbandingan Pre vs Post test & $<0,001$ & 0,783 & \\
\hline
\end{tabular}

Keterangan : *) uii wilcoxon

Tabel 3. Penurunan durasi dismenore primer dua kelompok

\begin{tabular}{lccc}
\hline & \multicolumn{2}{c}{$\begin{array}{c}\text { Latihan Spinning Intensitas } \\
\text { Sedang }\end{array}$} & $\begin{array}{c}\text { Nilai } \\
\boldsymbol{p}^{*}\end{array}$ \\
\cline { 2 - 4 } Durasi nyeri & $\begin{array}{c}\text { Melakukan } \\
\text { Latihan } \\
\mathbf{( n = 1 6 )}\end{array}$ & $\begin{array}{c}\text { Tidak } \\
\text { Latihan } \\
\mathbf{( n = 1 6 )}\end{array}$ & \\
\hline $\begin{array}{l}\text { Pre Test } \\
\text { Median }\end{array}$ & 12 & 12 & 0,729 \\
Rentang & $2-48$ & $2-48$ & \\
\hline $\begin{array}{l}\text { Post Test } \\
\text { Median }\end{array}$ & 1 & 12 & 0,004 \\
Rentang & $0-24$ & $2-48$ & \\
Perbedaan Pre vs Post test & 0,007 & 0,655 & \\
\hline
\end{tabular}

Keterangan : *) uii wilcoxon

Berdasarkan Tabel 4 didapat bahwa median penurunan intensitas pada kelompok intervensi sebesar 4 skor atau 90\%, sedangkan pada kelompok kontrol sebesar 0 skor atau $0 \%$ (tetap) dengan $\mathrm{p}<0,001$, artinya bahwa terdapat pengaruh intervensi terhadap penurunan intensitas nyeri.Median durasi intensitas pada kelompok intervensi sebesar 9 jam atau $87,5 \%$, sedangkan pada kelompok kontrol sebesar 0 skor atau 0\% (tetap) dengan $\mathrm{p}=0,006$, artinya bahwa terdapat pengaruh 
intervensi terhadap penurunan durasi nyeri.

Tabel 4. Pengaruh Spinning Exercise Intensitas Sedang terhadap Penurunan Gejala Dismenore Primer

\begin{tabular}{|c|c|c|c|}
\hline \multirow[b]{2}{*}{ Gejala Nyeri } & \multicolumn{2}{|c|}{$\begin{array}{l}\text { Latihan Spinning Intensitas } \\
\text { Sedang }\end{array}$} & \multirow{2}{*}{$\begin{array}{c}\text { Nilai } \\
\Delta\end{array}$} \\
\hline & $\begin{array}{c}\text { Melakukan } \\
\text { Latihan } \\
(\mathrm{n}=16)\end{array}$ & $\begin{array}{c}\text { Tidak } \\
\text { Latihan } \\
(\mathrm{n}=16)\end{array}$ & \\
\hline $\begin{array}{l}\text { Penurunan Intensitas } \\
\overline{\mathrm{x}}(\mathrm{SD}) \\
\text { Median } \\
\text { Rentang } \\
\text { \% Penurunan (Median) }\end{array}$ & $\begin{array}{c}4(1) \\
4 \\
2-6 \\
90 \%\end{array}$ & $\begin{array}{c}0(1) \\
0 \\
-2-2 \\
0 \%\end{array}$ & $<0,001$ \\
\hline $\begin{array}{l}\text { Penurunan Durasi } \\
\overline{\mathrm{x}}(\mathrm{SD}) \\
\text { Median } \\
\text { Rentang } \\
\% \text { Penurunan (Median) }\end{array}$ & $\begin{array}{c}12(14) \\
9 \\
-3-48 \\
87,5 \%\end{array}$ & $\begin{array}{c}1(3) \\
0 \\
-4-12 \\
0 \%\end{array}$ & 0,006 \\
\hline
\end{tabular}

Keterangan: Analisis uji mann whitney

\section{PEMBAHASAN}

Penelitian ini dilakukan selama bulan Desember 2018 sampai Januari 2019 di Asrama Putri Institusi Kebidanan di Kota Bandung dengan sampel sebanyak 32 responden memenuhi kriteria yang terbagi kedalam kelompok intervensi dan kelompok kontrol dengan jumlah masingmasing responden perkelompok sebanyak 16 mahasiswi.Kedua kelompok pada awal penelitian diberikan pre tes mengenai skala nyeri dan durasi/lamanya nyeri menstruasi selanjutnya untuk kelompok kontrol mereka beraktifitas seprti biasa tanpa melakukan olah raga selama waktu penelitian sedangkan untuk kelompok intervensi mereka diwajibkan mengikuti program latihan spinning dengan sepeda statis selama 9 kali latihan yang dilaksanakan dengan interval 1 hari pada jam tertentu sesuai jadwal dengan pendampingan instruktur. Setelah melakukan latihan spinning sesuai jadwal ditunggu sampai dengan mendapatkan haid siklus selanjutnya, begitupun dengan kelompok kontrol yang tidak melakukan spinning keduanya diberikan kuesioner kembali untuk dilakukan post tes kembali.

Frekuensi nyeri akan menurun sesuai dengan bertambahnya usia. Hal ini terjadi karena adanya kemunduran saraf uterus akibat penuaan. Median usia menarche kedua kelompok yaitu pada usia 12 tahun 
dengan nilai $\mathrm{p}=0,416$. Untuk median lama menstruasi kedua kelompok adalah 7 hari dengan nilai $\mathrm{p}=0.747$. Median siklus menstruasi kedua kelompok adalah 25 hari dengan nilai $\mathrm{p}=1.000$. Pada penelitian ini, umur, usia menarche, lama menstruasi, siklus menstruasi tidak menunjukkan perbedaan yang bermakna antar kelompok perlakuan dan kontrol. Kedua kelompok ini memiliki homogenitas data karakteristik sehingga layak untuk dibandingkan. Ada beberapa hal yang dilakukan dalam penelitian ini untuk menjaga kepatuhan responden diantaranya adalah penjelasan tentang tujuan dan cara penelitian serta memberikan pendampingan selama melakkan latihan spinning.

Pada data pre test berdasarkan uji analisis dengan chi kuadrat nilai $\mathrm{p}>0,05$ artinya tidak terdapat perbedaan gejala intensitas nyeri maupun durasi nyeri antara intervensi dengan kontrol. Pada post test berdasarkan uji chi kuadrat nilai $\mathrm{p}<0,05$ artinya terdapat perbedaan gejala skor intensitas nyeri maupun durasi nyeri antara intervensi dengan kontrol. Terlihat gejala intensitas nyeri pada kelompok intervensi lebih banyak yang menurun dengan skala 0 s.d 3, sedangkan pada kelompok kontrol masih tetap dengan skala 4 s.d. 6. Begitu juga dengan durasi nyeri pada kelompok intervensi hampir 50\% durasi 0 jam, sedangkan pada kelompok control hampir sebagian besar dengan durasi 6 s.d 48 jam.

\section{Penurunan Intensitas dan Durasi Dismenore}

Mekanisme penurunan intensitas dan durasi dismenore sesuai dengan patofisiologinya bahwa dismenore primer terjadi karena adanya mekanisme prostaglandin endometrial dan leukotrien. Setelah terjadi proses ovulasi sebagai respons peningkatan produksi progesteron, asam lemak akan meningkat dalam fosfolipid membran sel. Kemudian asam arakidonat dan asam lemak omega-7 lainnya dilepaskan dan memulai suatu aliran mekanisme prostaglandin dan leukotrien dalam uterus yang berakibat pada termediasinya respons inflamasi, tegang saat menstruasi (menstrual cramps), dan molimina menstruasi lainnya. Hasil metabolisme asam arakidonat adalah prostaglandin (PG) F2-alfa, yang merupakan suatu siklooksigenase (COX) yang mengakibatkan hipertonus dan vasokonstriksi pada miometrium sehingga terjadi iskemia dan nyeri menstruasi. Untuk mengurangi dismenore primer tersebut, maka salah satunya adalah dengan merangsang pelepasan endorfin, yang bertindak sebagai analgesik non- 
spesifik yang bekerja untuk menghambat dan membantu menciptakan anti nyeri alami di dalam tubuh.

Perbedaan penurunan gejala nyeri dismenore primer berdasarkan intensitas nyeri pada kelompok mahasiswi yang diberikan spinning exercise intensitas sedang terlihat pada tabel 4.1.3 dimana data analisis dengan uji mann whitney menunjukkan bahwa nilai $\mathrm{p}=0,643$ sebelum diberi perlakuan (siklus I/pretest), intensitas dismenore pada kelompok intervensi maupun kontrol secara statistik tidak ada perbedaan yang bermakna. Median pre test menunjukan skala nyeri 5 dengan rentang 4 - 6 pada kedua kelompok. Pada post test terdapat perbedaan skala nyeri pada kedua kelompok, berdasarkan uji Wilcoxon, pada kelompok intervensi menunjukkan penurunan intensitas nyeri yang bermakna $(\mathrm{p}<0,001)$ dimana kelompok yang mendapat intervensi median skala nyeri menurun menjadi 1 dengan rentang $0-3$, sedangkan pada kelompok kontrol median skala nyeri masih tetap sebesar 5 dengan rentang $4-6$.

Perbedaan penurunan gejala nyeri dismenore primer berdasarkan durasi nyeri pada kedua kelompok terlihat pada Tabel dari hasil analisis diatas didapat bahwa berdasarkan uji Wilcoxon, pada kelompok intervensi menunjukkan penurunan durasi nyeri yang bermakna $(\mathrm{p}=0,007)$, sedangkan pada kelompok kontrol tidak menunjukkan penurunan durasi nyeri yang bermakna $(p=0,655)$. Data pre test median durasi nyeri 12 jam dengan rentang $2-48$ jam, baik pada kelompok intervensi maupun kempokok kontrol $(p=0,729)$. Pada post test kelompok yang mendapat intervensi median durasi nyeri menurun menjadi 1 jam dengan rentang $0-24$ jam, sedangkan pada kelompok kontrol median durasi nyeri masih tetap sebesar 12 jam dengan rentang $2-24$, berdasarkan uji mann whitney nilai $\mathrm{p}=0,004$, artinya bahwa terdapat perbedaan durasi nyeri pada post tes antara kelompok intervensi dan kelompok kontrol. Dari penelitian ini diperoleh pula hasil uji statistik pengaruh intervensi latihan spinning intensitas sedang terhadap penurunan gejala intensitas nyeri dan durasi nyeri dengan uji mann whitney dimana nilai $\mathrm{p}<0.001$ untuk pengaruh intervensi terhadap penurunan intensitas nyeri dan nilai $\mathrm{p}=0,006$ untuk pengaruh intervensi terhadap penurunan durasi nyeri. Sedangkan untuk prosentase penurunan intensitas nyeri pada kelompok intervensi sebesar 90\% dan penurunan durasi nyeri sebesar 87,5\%. Artinya bahwa 
terdapat pengaruh intervensi terhadap penurunan gejala nyeri dismenore primer.

\section{Pengaruh Spinning Exercise terhadap Penurunan Dismenore}

Hasil penelitian ini sesuai dengan penelitian yang dilakukan oleh Abbaspour (2006) dimana keparahan dan durasi dismenore berkurang dengan adanya olahraga $(p<0,01) .{ }^{15}$ Olahraga bersepeda dapat menurunkan derajat dismenore karena olahraga bersepeda statis merupakan salah satu dari macam olahraga aerobik dan merupakan olahraga yang mempunyai unsur rekreasi dan relaksasi. Olahraga bersepeda dapat menghasilkan hormon endorphine. Endorphine adalah neuropeptide yang dihasilkan tubuh pada saat relaks/tenang. Endorphine dihasilkan di otak dan susunan syaraf tulang belakang. Hormon ini dapat berfungsi sebagai obat penenang alami yang diproduksi otak dimana dapat memberikan rasa nyaman dan mengurangi rasa nyeri pada saat kontraksi endometrium. Olahraga bersepeda terbukti dapat meningkatkan kadar hormon endorphine empat sampai lima kali dalam darah. Sehingga, semakin banyak melakukan olahraga besepeda maka akan semakin tinggi pula kadar hormon endorphine dalam darah.
Ketika seseorang melakukan olahraga bersepeda maka akan memberikan rangsangan proprioseptif, yang akan ditransmisi melalui serabut besar ke formatio reticularis, thalamus dan sistem limbik, dari sini akan terjadi pelepasan endorphine, yang akan mengaktifkan suatu jalur inhibisi nyeri desendens (ke aliran darah) dan menghambat transmisi serta pengaturan nyeri sehingga dapat mengurangi derajat dismenore. Selain itu olahraga bersepeda juga meningkatkan efesiensi kerja paru, paningkatkan jumlah dan ukuran pembuluh darah sehingga oksigen dan aliran darah dapat tersalurkan ke organ reproduksi yang mengalami vasokonstriksi

Perubahan fisiologi dan psikologi yang positif akan terjadi apabila seseorang dilatih dengan program intensitas latihan yang intensif berlandaskan pada prinsip overload, secara progresif menambah beban kerja, jumlah pengulangan (repetition), gerakan serta kadar dari intensitas repetisi tersebut, dalam penelitian ini intensitas yang digunakan adalah intensitas sedang. Intensitas sedang dapat ditentukan melalui FITT (Frequensi, Intensity, Time, Type). Beberapa riset menjelaskan dengan melakukan latihan olah raga maka tubuh akan menghasilkan hormon endorphine yang 
dihasilkan di otak dan susunan syaraf tulang belakang. Hormon ini dapat berfungsi sebagai obat penenang alami yang diproduksi otak sehingga menimbulkan rasa nyaman melalui teknik relaksasi dan juga rekreasi yang ditimbulkannya sehingga dapat digunakan untuk menurunkan gejala nyeri yang ditimbulkan oleh dismenore.

Sejalan dengan hasil penelitian Marsida dkk melakukan observasi analitik dengan pendekatan kohort pada tahun 2012 pada mahasiswi kedokteran di Malang. Selama sebulan sejumlah 38 mahasiswi dengan dismenore primer yang dikelompokkan kedalam kelompok perlakuan dengan olah raga bersepeda dan kelompok kontrol tidak berolah raga. Hasil riset didapatkan bahwa kelompok perlakuan yang rutin melakukan olahraga bersepeda (2-3x/ minggu, 30-60 menit) selama 1 bulan mengalami penurunan derajat dismenore sebesar $78,9 \%$ atau sebanyak 15 mahasiswi. Sedangkan pada kelompok kontrol sebesar $84,2 \%$ atau sebanyak 16 mahasiswi derajat dismenorenya tetap. Hasil analisis menggunakan uji-t berpasangan dengan tingkat kepercayaan 95\% dan $\mathrm{p}<0,05$ didapatkan nilai signifikan sebesar 0,000 dan besar pengaruh bersepeda terhadap pengurangan dismenore sebesar $66,3 \%$.

\section{KESIMPULAN}

Terdapat pengaruh spinning exercise intensitas sedang terhadap penurunangejala dismenore pada mahasiswi kebidanan yang melakukan latihan

\section{UCAPAN TERIMA KASIH}

Kepada Direktur, Pengelola Asrama dan mahasiswi D III Kebidanan tingkat I Poltekkes TNI AU Ciumbuleuit dan seluruh pihak pendukung yang terlibat dalam penelitian ini.

\section{REFERENSI}

Anisa MV. (2015) The Effect of Exercise on Primari Disemenorrbea Majority.

Arjuna F(2013). Menjaga Kebugaran dengan Bersepeda. Yogjakarta UN Jurusan Pendidikan Kesehatan dan Rekreasi

Auguntari IT (2018). Aktivitas Fisik HIIE pada Remaja Obesitas dan Self Esteem. Jurnal Pendidikan Jasmani dan Olahraga.

BKKBN.(2011) Kajian Profil Penduduk Remaja.

Daley AJ. Exercise and Primary Dysmenorrhea (2008). A Comprehensive and Critical Review of the Literature. Uviversity of Birmingham Clinical Sciences Building

Fatih Kay DN, Mustafa Said Erzeybek (2018) Effect of Spinning Cycling Training on Body Composition in Woman. Journal of Education and Training Studies

Habibi N Huang (2016). Prevalence of Primary Dysmenorrhea and Factors Associated. Pain Management Nursing

K Renuka SJ (2015) Sretching Exercise Therapy and Primary Dysmenorrhea Nursing Perspective. IOSR Juournal of Nursing and Health Science 
Kannan P, Chapple CM, (2015). Menstrual Pain and Quality of Life in Women With Primary Dysmenorrhea. Elsevier

Klika RJ. (2007). Efficacy of Cycling Training Based on A Power Field Test. Journal of Strength and Conditioning Research Luciene Ferreira Azevedo MR.(2014)High Intensity Intermittent Exercise Training for Cardiovascular Disease. Novel Physiotherapies

Marsida Fatmawati AH, Isbandiyah (2013). Pengaruh Olabraga Bersepeda dalam Menurunkan Derajat Dismenore pada Mahasiswi Kedokteran di Malang. Fakultas Kedokteran Universitas Muhamadiyah Malang
Moeloek NF. (2016)Germas Wujudkan Indonesia Sebat. Kementrian Kesehatan Republik Indonesia

Nunik Purwanti LW, Rif Helmi Setiawan (2012). Effect of Aerobic Exercise on Menstrual Pain. Faculti of Nursing Airlangga Univ

Peraturan Menkes RI Nomor 28 Tahun 2017 Tentang Izin dan Penyelenggaraan Praktik Bidan

Peraturan Menkes RI Nomor 28 Tahun 2017 Tentang Izin dan Penyelenggaraan Praktik Bidan

Santoso Giriwijono DZS(2013). Ilmu Kesehatan Olahraga. Rosdakarya. 